\title{
Comparative Study of Significance of Serum Cystatin-C, Serum Creatinine and Microalbuminuria Estimation in Patients of Early Diabetic Nephropathy
}

\author{
Mukherjee Brijesh ${ }^{1 *}$ and Patra Saurav²
}

${ }^{1}$ Department of Biochemistry, Hi-Tech Medical College and Hospital, Rourkela, Odisha, India

${ }^{2}$ Department of Biochemistry, Kalinga Institute of Medical Sciences, Bhubaneswar, Odisha, India

\begin{abstract}
Background: Diabetes has become the most common single cause of End Stage Renal Disease (ESRD) in most countries. About $20-30 \%$ of patients with type 1 or type 2 Diabetes develop evidence of nephropathy. Recent studies have now demonstrated that the onset and course of DN can be ameliorated to a significant degree by several interventions but these interventions have their greatest impact if instituted at a point very early in the course
\end{abstract} of the development of this complication.

Materials and methods: The diabetic patients visiting the Nephrology and Medicine OPDs were selected and evaluated for serum cystatin $\mathrm{C}$, blood urea, serum creatinine and urine microalbumin. The patients were divided into three groups according to duration of diabetes. Group 1 with diabetes between 5-10 years, group 2 with diabetes between $10-15$ years and group 3 with diabetes more than 15 years All statistical analyses were done using Microsoft Excel for Windows VII version, SPSS (Statistical Package for Social Sciences) and GraphPad Prism 6.0 version.

Results: Serum cystatin C was significantly increased in Group $2(p<0.01)$ along with increase in urine micral but serum creatinine levels showed no significant changes. ROC for cystatin $C$ was 0.93 where as for creatinine it was 0.79 .

Conclusion: Serum cystatin $\mathrm{C}$ is a better marker for early diabetic nephropathy than serum creatinine and equally effective as urine micral.

Keywords: ESRD; Cystatin C; Microalbumin; Creatinine

\section{Introduction}

The American Diabetes Association (ADA) defined diabetes as "a group of metabolic disorders characterized by hyperglycemia resulting from defects in insulin secretion, insulin action or both" [1]. In recent times it has been observed that there has been a steep rise in the prevalence of metabolic syndrome [2] and of type 2 diabetes [3] worldwide, which is extremely pronounced in Asian countries [3] and is particularly remarkable in India [4]. Diabetes prevalence is increasing in every country with a rise in its term of claiming of human lives as well as the costs to society. Estimated surveys show that:

- In 2011, 366 million people, or approximately $8.3 \%$ of the world's adult population, lived with diabetes and according to IDF data it has risen to 371 million in 2012 [5].

- By 2030 this number is expected to grow to 552 million [6].

- China has the largest number of people with diabetes in the world (92 million).

- Worldwide, only half of all people with diabetes are diagnosed [6].

In a developing country like India there has been a rapid change in the life style of people. Obesity and Diabetes Mellitus go hand in hand and have become major health problems. The prevalence rate of diabetes has increased dramatically over the years since the time the first national survey was undertaken, in 1971. At that time the prevalence was $2.3 \%$ in the urban areas and $1.2 \%$ in the rural areas. The most recent studies suggest prevalence rate of between $15-20 \%$ in urban areas and half of that in rural areas. In 2011, India had 62.4 million people with type 2 diabetes, compared with 50.8 million the preceding year, according to the International Diabetes Federation (IDF) and the Madras Diabetes Research Foundation. The nationwide prevalence of diabetes in India now is $9 \%$ with an increase of upto $20 \%$ in the relatively prosperous southern cities. By 2030, the IDF predicts, India will have 100 million people with diabetes. Complications of diabetes, such as coronary artery and peripheral vascular disease, stroke, diabetic neuropathy, gangrene, renal failure and blindness leads to increasing disability, reduced life expectancy and enormous health costs. Diabetes has become the most common single cause of End Stage Renal Disease (ESRD) in most countries; this is due to the fact that diabetes, particularly type 2 , is alarmingly increasing in prevalence rate, diabetic patients now live longer and patients with diabetic ESRD are now accepted for treatment in ESRD programs where formerly they had been excluded. About $20-30 \%$ of patients with type 1 or type 2 Diabetes develop evidence of nephropathy. Recent studies have now demonstrated that the onset and course of DN (Diabetic Nephropathy) can be ameliorated to a significant degree by several interventions but these interventions have their greatest impact if instituted at a point

${ }^{*}$ Corresponding author: Dr. Mukherjee Brijesh, Assistant Professor, Department of Biochemistry, Hi-Tech Medical College and Hospital, Rourkela, Odisha, India, Tel: 919437115479; E-mail: taararia@gmail.com

Received September 07, 2014; Accepted December 23, 2014; Published December 25, 2014

Citation: Brijesh M, Saurav P (2015) Comparative Study of Significance of Serum Cystatin-C, Serum Creatinine and Microalbuminuria Estimation in Patients of Early Diabetic Nephropathy. J Diabetes Metab 6: 490. doi:10.4172/2155-6156.1000490

Copyright: $\odot 2015$ Brijesh M, et al. This is an open-access article distributed under the terms of the Creative Commons Attribution License, which permits unrestricted use, distribution, and reproduction in any medium, provided the original author and source are credited. 
very early in the course of the development of this complication. Estimation of the Glomerular Filtration Rate (GFR) is the most widely used test of renal function and reflects the kidney's ability to clear a particular substance from plasma. The most precise and accurate methods for estimating GFR are based upon determinations of plasma clearance of substances like 51Cr- EDTA, iothalamate or iohexol. These so called "gold standard" methods require injection of an exogenous radioactive or contrast agent which are cumbersome, expensive and impractical in a clinical setting as well as for larger research studies. Therefore, the measurement of endogenous blood substances to estimate GFR is common practice. For several decades clinicians have relied on measurements of serum creatinine as a rapid first line test to determine GFR. This test is convenient and cheap, but results are affected by age, sex, muscle mass, diet, race and tubular creatinine secretion, particularly when GFR is reduced. Thus, there has been an ongoing search for suitable alternative endogenous markers of GFR.

This present study aims at finding out the role of cystatin C, [7] a relatively new marker for diabetic nephropathy. This study will also involve comparison of cystatin $\mathrm{C}$ with serum creatinine and microalbuminuria (established parameters for diagnosis of DN) and to find out whether cystatin $\mathrm{C}$ can be a better marker for detection of early diabetic nephropathy.

\section{Materials}

The study was carried out in the Department of Biochemistry, after approval was obtained from the Institutional Ethics Committee on 8th October, 2011, from November 2011 to April 2013 under the guidance of Prof Dr Ashok Kumar Das and in collaboration with the Department of Nephrology and Medicine, KIMS. The diabetic patients visiting the Nephrology and Medicine OPDs were selected and evaluated for serum cystatin $\mathrm{C}$, blood urea, serum creatinine and urine microalbumin. The patients were divided into three groups as follows: Group I: comprised of 30 patients with duration of DM (diabetes mellitus) more than five years and less than ten years. Group II: comprised of 48 patients with DM duration between 10 to 15 years Group III: comprised of 22 patients with history of DM more than 15 years.

The following inclusion and exclusion criteria were used to form the patient groups:

\section{Inclusion criteria}

1. Diabetics will history of $>5$ yrs duration

2. $\mathrm{HbAlc}>8 \%$

3. Serum Cholesterol $>250 \mathrm{mg} / \mathrm{dl}$

4. Consent given by the patient for compliance with study protocol

5. Age $>30$ years and $<70$ years.

\section{Exclusion criteria}

1. Patients of thyroid dysfunction

2. Patients on glucocorticoid therapy

3. End Stage Renal Disease

4. Diabetic patient with macroalbuminuia

5. Current participation in another clinical trial

Control group - 100 age and sex matched healthy individuals were taken as control.
The following methods were employed for performing the various biochemical parameters:

- Plasma Glucose was measured by Hexokinase method in Autoanalyzer

- Serum Creatinine was measured by Jaffe's method (Compensated Method for Serum and Plasma in Autoanalyzer

- Serum Urea was measured by Kinetic method using urease and glutamate dehydrogenase in Auto-analyzer

- Glycated Hemoglobin was measured by HPLC (high performance liquid chromatography) in D10 Analyzer

- Microalbumin in urine was assayed using Immunoturbidimetry in Auto Analyzer

- Serum Cystatin C was measured by immunotubidimetric method in Semi-auto Analyzer.

\section{Results and Discussions}

Diabetic patients are 17 times more prone to develop kidney disease than the normal population. The prevalence of DN is related to the prevalence of diabetes, which varies in different ethnic groups and geographical areas. The peak onset of $\mathrm{DN}$ is between $10-15$ years after the onset of diabetes, as suggested in the study by Adler, et al. [8] Patients who do not develop proteinuria after 20-25 years have only $1 \%$ risk of nephropathy, Gall, et al. [9]. A clinic - based study conducted at Dr Mohan's Diabetes Specialties Centre (DMDSC) revealed that $9 \%$ of patients had proteinuria and $20-25 \%$ had microalbuminuria at any given time. In the Chennai Urban Population Study (CUPS), it was found that the prevalence of overt proteinuria was $2.2 \%$ and microalbuminuria was $26.3 \%$. In the CURES population [10], the prevalence of overt proteinuria and microalbuminuria were, respectively, $2.2 \%$ and $26.9 \%$. The prevalence rate is related to the duration of diabetes and increases in presence of risk factors like high HbAlc levels, hyperlipedemia and hypertension. These risk factors have been elaborated by studies done by Timothy et al. [11]. Taking all the above factors in to account, the study design of this study was framed accordingly. The study included diabetic patients with history of more than five years from the date of first detection of the disease and having two risk factors (Serum Cholesterol $>250 \mathrm{mg} \%$ and $\mathrm{HbA} 1 \mathrm{c}>8 \%$ ). This increased the chances of inclusion and evaluation of DN patients in the study, as evident from the various cited studies. Then, the patients were divided in to three groups according to the duration of DM (5-10 years, 10-15 years and $>15$ years respectively).

\section{Body mass index}

In this study it was found out that BMI was not significantly different $(\mathrm{p}=0.61)$ in the patient group (Mean $\pm \mathrm{SD}=21.71 \pm 1.87)$ when compared with the control group (Mean $\pm \mathrm{SD}=22.59 \pm 1.79$ ). The BMI in group 1 (Mean $\pm \mathrm{SD}=22.94 \pm 1.38$ ) was higher than in control group but was not statistically significant $(\mathrm{p}=0.84)$. Similarly BMI in group $2($ Mean $\pm \mathrm{SD}=21.63 \pm 1.89)$ and group 3 (Mean $\pm \mathrm{SD}=20.19 \pm 1.03)$ showed no statistically significant increase or decrease when compared with the control group with $\mathrm{p}=0.58$ and $\mathrm{p}=0.17$ respectively. Meltzer et al. [12] in their study found out that the BMI of Type II diabetics decreases with increasing duration of the disease. Similar findings were observed in this study but they were not statistically significant.

\section{Blood pressure}

Systolic Blood Pressure of the patient group (Mean $\pm \mathrm{SD}=138.3 \pm$ 
$14.88 \mathrm{~mm}$ of $\mathrm{Hg}$ ) and Diastolic Blood Pressure (Mean $\pm \mathrm{SD}=87.28 \pm$ $8.06 \mathrm{~mm}$ of $\mathrm{Hg})$ was significantly higher $(\mathrm{p}=<0.01)$ than in the control group in which Systolic BP and Diastolic BP were $117.35 \pm 4.91 \mathrm{~mm}$ of $\mathrm{Hg}$ and $78.06 \pm 3.50 \mathrm{~mm}$ of $\mathrm{Hg}$ respectively. The Systolic BP in Group I, Group II and Group III were $128.07 \pm 10.98,139.08 \pm 13.41$ and $150.55 \pm 12.46 \mathrm{~mm}$ of $\mathrm{Hg}$ respectively. The $\mathrm{p}$ value was less than 0.01 in all the groups when compared with the control group. Similarly the Diastolic BP's were $80.73 \pm 5.33,88.96 \pm 7.16$ and $92.55 \pm 7.22 \mathrm{~mm}$ of $\mathrm{Hg}$ in Group I, Group II and Group III respectively. The p value was less than 0.01 in Group II and Group III compared to Control Group but it was 0.44 when Group I was compared with Control. Moreover the $\mathrm{p}$ value was $<0.01$ when Group III and Group I were compared. These observations suggest that BP is a risk factor in development of $\mathrm{DN}$ in diabetic patients and it increases with the progress of the disease. These findings are consistent with the findings of United Kingdom Prospective Diabetes Study (UKPDS) [13] and studies done by Adler et al. [14].

\section{Fasting blood glucose}

The Fasting Blood Glucose levels in the control group was $85.02 \pm$ $7.81 \mathrm{mg} / \mathrm{dl}$ and in cases group was $155.08 \pm 26.22 \mathrm{mg} / \mathrm{dl}$. The fasting glucose levels in Group I, Group II and group III were respectively $149.37 \pm 25.34,153.54 \pm 25.49$ and $166.23 \pm 25.64 \mathrm{mg} / \mathrm{dl}$. All the means in different groups were significantly more than the mean of control group $(\mathrm{p}<0.01)$. However the $\mathrm{p}$ value was not significant when the three groups were compared with each other. These results, as expected, show that fasting glucose levels are much higher in patient groups. The significant thing noted was FBS has no predictive value in the progress of DN as there was no significant rise in its value with increasing duration of the disease. These findings corroborated well with findings of Diabetes Control and Complications Trial (DCCT) Research Group [15].

\section{Glycated Hemoglobin (HbAlc)}

The HbAlc level in the Control group was $4.50 \pm 0.34 \%$ and in the Cases it was $10.40 \pm 1.35 \%$. There was significant increase $(\mathrm{p}<0.001)$ in cases compared to the controls. The HbAlc levels in the different groups were $9.68 \pm 0.75 \%$ (Group I), $10.37 \pm 1.21 \%$ (Group II) and 11.43 $\pm 1.61 \%$ (Group III). All these three values were significantly higher when compared with the value of control $(\mathrm{p}<0.001)$. The $\mathrm{p}$ values were $0.36,0.38$ and 0.02 when Group I was compared with Group II, Group II was compared with Group III and Group I was compared with Group III. These observations show that HbAlc levels are higher in $\mathrm{DN}$ patients and hence poor glycemic control, increase the chances of development of micro vascular complications. Moreover the glycemic control is progressively lost with increase duration of the disease. These findings are very much consistent with findings Straton et al. [16] and textbooks on diabetes.

\section{Serum cholesterol}

The Mean \pm SD value in the Control Group was $175.15 \pm 10.56 \mathrm{mg} /$ $\mathrm{dl}$ and in the Cases it was $364.05 \pm 57.69 \mathrm{mg} / \mathrm{dl}$. There was significant difference in the mean values $(\mathrm{p}<0.001)$. The Mean \pm SD values in Group I, Group II and Group III were 332.8 \pm 42.91, $363.42 \pm 58.77$ and 408.05 $\pm 42.55 \mathrm{mg} / \mathrm{dl}$ respectively. All these values were significantly higher $(\mathrm{p}<0.001)$ than the control value. There was also significant increase in serum cholesterol levels ( $\mathrm{p}=0.08$ ) in Group III when compared with Group I. Hyperlipidemia is an established risk factor in development of DN in diabetics as demonstrated by studies done by Shestakova, et al. and Jandeleit-Dahm, et al. $[17,18]$ This study also demonstrated the same fact as observed by earlier researchers quoted above. Moreover it was found out that serum cholesterol levels increase significantly in later stages of the disease.

\section{Serum urea}

The mean serum urea level in the Control Group was $26.56 \mathrm{mg} / \mathrm{dl}$ with a standard deviation of \pm 6.07 whereas the mean of total cases was $34.82 \mathrm{mg} / \mathrm{dl}$ with a standard deviation of \pm 16.49 . Though the mean was higher in cases but this increased value was not statistically significant $(\mathrm{p}=0.17)$. The Mean \pm SD in the Groups I, II and III were $24.97 \pm 5.85$, $29.92 \pm 8.86$ and $58.95 \pm 15.82 \mathrm{mg} / \mathrm{dl}$ respectively. There was significant increase $(p<0.001)$ when Group III was compared with Group I and when Group III was compared with Group II. These observations point towards the fact that serum urea is a non specific marker to know the renal status in patients of DN. However in the later stages of the disease when renal function is compromised to a higher degree there is significant increase. Nsonwu et al. [19] in their study also got the findings that Serum Urea levels increase in long standing diabetes cases only.

\section{Microalbuminuria}

All the patients in Control Group had microalbuminuria less than $20 \mathrm{mg} / \mathrm{l}$. The average value was $7.94 \pm 2.77 \mathrm{mg} / \mathrm{l}$. The average microalbuminuia in the Cases group was $51.71 \pm 51.41 \mathrm{mg} / \mathrm{l}$. There was very significant increase in cases when compared to controls $(\mathrm{p}<0.001)$ The microalbumin in urine for the Group I (Diabetics between 5-10 years duration) was $15.65 \pm 5.30 \mathrm{mg} / \mathrm{l}$. This value was found to be under normal levels and hence it was concluded microalbuminuria had not set in this Group. There was no significant increase when compared with the controls $(\mathrm{p}=0.08)$. The Mean \pm SD in Group II (Diabetics between $10-15$ years duration) was $37.58 \pm 17.57 \mathrm{mg} / \mathrm{l}$. This value was above the normal range and it was observed that microalbuminuria, the hallmark of DN was present in this group. There was significant increase when compared with the controls $(\mathrm{p}<0.001)$. The Mean \pm SD in Group III (Diabetics with history of more than 15 years) was $131.68 \pm 51.54 \mathrm{mg} / \mathrm{l}$. This clearly demonstrated the fact that levels of microalbumin in urine increases with increasing duration of diabetes especially in patients with poor glycemic control and hyperlipedemia (the inclusion criteria of this study was $\mathrm{HbAlc}>8 \%$ and cholesterol levels more than $250 \mathrm{mg} /$ dl). As expected, there was significant increase compared to the control group. It was also noted that during initial selection of the cases for the study many diabetics with more than 15 years duration of the disease had macroalbuminuria and hence were rejected (one of the exclusion criteria was patients with macroalbuninuria). All these findings were summarized to give the conclusion that microalbuminuria appears mostly after 10 years of diabetes and then increases with further increase in the duration of the disease. Many patients after 15 years of the disease have macroalbuminuia and frank proteinuria. These observations are well supported by works of other researchers. Kundu, et al. [20] found out that urinary microalbumin, $\mathrm{HbA} 1 \mathrm{c}$ levels were significantly higher in the cases and microalbumin levels were linearly correlated to the duration of diabetes and HbAlc. The National Kidney Foundation Kidney Disease Outcomes Quality Initiative (NKF KDOQI) stated that all diabetics with more than five years of the disease should be screened for microalbuminuria, although it appears after 10 years of the disease [21]. Rahlenbeck, et al. in his study got results similar to this study [22]. They found a significant correlation of $\mathrm{DN}$ with duration of disease and presence of microalbumin in patients with more than 10 years history of diabetes and $\mathrm{HbAlc}$ more than $8 \%$. 


\section{Serum creatinine}

The Mean \pm SD levels of serum creatinine in the Control Group were $0.7 \pm 0.06 \mathrm{mg} / \mathrm{dl}$. The Mean \pm SD in Cases Group were $0.94 \pm 0.33$ $\mathrm{mg} / \mathrm{dl}$. There was significant increase in levels of S.Creatinine in cases compared to controls $(\mathrm{p}<0.01)$. Group I (Diabetics between $5-10$ years) had average levels of creatinine of $0.74 \pm 0.08 \mathrm{mg} / \mathrm{dl}$. This value was within normal range of serum creatinine in both males and females. There was no significant increase in this group compared to control group ( $\mathrm{p}=0.50$ ). The Mean \pm SD levels in Group II (Diabetics between 10 - 15 years) were $0.87 \pm 0.08 \mathrm{mg} / \mathrm{dl}$. It was observed that there was no significant increase in this group compared to control group $(p=0.09)$ and the mean value of this group was well within normal range of serum creatinine values for both males and females. This is contrary to findings of microalbumin whose mean values were significantly high in Group II compared to Control Group. However the Mean \pm SD of creatinine in Group III was $1.51 \pm 0.22 \mathrm{mg} / \mathrm{dl}$. This was higher than normal range and significantly higher than Control Group $(\mathrm{p}<0.001)$. There was also significant increase in Group III compared to Group II $(p<0.001)$. All these above findings suggest that serum creatinine values do not increase significantly in early stages of DN but show increase after there is substantial renal damage as depicted by high values of microalbumin in Group III (Diabetics more than 15 years). These findings are consistent with findings of Gover et al. [23] and Enyioma et al. [24].

\section{Serum cystatin C}

The Mean \pm SD for the Control Group was $0.78 \pm 0.08 \mathrm{mg} / \mathrm{l}$ and for the Cases Group it was $1.15 \pm 0.25 \mathrm{mg} / \mathrm{l}$. There was significant increase the cases when compared with the controls $(\mathrm{p}<0.001)$. Moreover the average value of the cases was above the normal range. The Mean \pm SD in Group I, Group II and Group III were $0.87 \pm 0.08,1.19 \pm 0.14$ and $1.44 \pm 0.18 \mathrm{mg} / \mathrm{l}$ respectively. There was no significant increase in Group I ( $\mathrm{p}=0.26)$ compared to the controls and the average value in this group was within normal range. However there was significant increase in Group II compared to control $(\mathrm{p}<0.001)$ and the average value in this group was above the normal range. These findings showed that serum cystatin levels were increased significantly in diabetics with history of more than 10 years. It has been already discussed that serum creatinine Levels in Group II were not significantly increased in this study. So it was inferred that serum cystatin $\mathrm{C}$ is earlier marker of $\mathrm{DN}$ in comparison to serum creatinine. A number of studies conducted have also got similar findings, for example the studies done by Premratne et al. [25] and Buysschaert et al. [26]. There was also significant increase in Group III values compared with controls. It was earlier discussed that serum creatinine values too were increased in Group III (Diabetics with history of more than 15 years). So it can be said that both cystatin $c$ and creatinine are good markers of DN when disease has advanced. This finding again is in accordance with findings of Christensson et al. [27] and Peralta et al. [28]. Christensson et al. concluded that serum cystatin $\mathrm{C}$ performed better compared with serum creatinine even when measured enzymatically, to detect mild diabetic nephropathy. However, serum creatinine was as efficient as serum cystatin $\mathrm{C}$ to detect advanced diabetic nephropathy.

\section{eGFR by creatinine based cockcroft gault formula and cystatin $\mathrm{C}$ based formula}

The Mean \pm SD of eGFR by creatinine based formula for Control Group, Total Cases, Group I, Group II and Group III were 103.64 \pm $21.61,81.31 \pm 27.35,99.91 \pm 17.28,89.34 \pm 14.09$ and $38.41 \pm 10.26$ respectively. There was no significant decrease in Cases Group, Group
I and Group II compared to Control Group ( $\mathrm{p}=0.30,0.87,0.51$ ). But there was significant decrease in Group III when compared to Control Group ( $\mathrm{p}=0.0025)$. The Mean \pm SD of eGFR by cystatin $\mathrm{c}$ based formula for Control Group, Total Cases Group, Group I, Group II and Group III were $110.53 \pm 18.07,67.49 \pm 23.11,96.17 \pm 14.73,60.04 \pm 11.29$ and $44.64 \pm 9.39$ respectively. There was no significant decrease in Group I compared to Control Group $(\mathrm{p}=0.43)$. But there was significant decrease in Group II and Group III when compared to Control Group ( $\mathrm{p}=0.0053$ and 0.0003 ). There was also significant decrease in the Cases group when compared with the Control Group $(\mathrm{p}=0.02)$. All the above findings conclusively prove that eGFR by cystatin $\mathrm{C}$ is better to know the renal status in patients of early DN detected by microalbuminuria. This finding is well supported by works of Mussap, et al. (Mussap and colleagues showed that cystatin $\mathrm{C}$ might be considered as an alternative and more accurate serum marker than serum creatinine or the CG estimate of GFR in discriminating type 2 diabetic patients with reduced GFR from those with normal GFR) [29]. A meta-analysis of combined data from 46 studies on different age groups of healthy volunteers and patients with different degrees of kidney impairment, caused by a diverse group of conditions, also demonstrated serum cystatin $\mathrm{C}$ was clearly superior to serum creatinine as a marker used for GFR measurement [30].

\section{Pearson coefficient of correlation, regression analysis and ROC curves of renal parameters}

In Group II, there was high significant correlation between micral and serum cystatin $\mathrm{C}(\mathrm{r}=0.78, \mathrm{p}<0.0001)$ but correlation between micral and serum creatinine was moderate $(r=0.31, p=0.04)$. Similarly correlation between micral and eGFR calculated by cystatin $\mathrm{C}$ based formula $(\mathrm{r}=-0.69, \mathrm{p}<0.001)$ was higher than correlation between micral and eGFR calculated by serum creatinine based formula $(r=-0.156$, $\mathrm{p}=0.291$ ). The correlation between cystatin $\mathrm{C}$ and creatinine was also moderate $(\mathrm{r}=0.30, \mathrm{p}=0.04)$. As already discussed, the patients in this group had microalbuminuria, raised serum cystatin $C$ value and normal serum creatinine values. The regression analysis in this group with micral as the independent variable also showed that cystatin $C$ was superior to serum creatinine ( $R 2=0.6$ and 0.09 with $\mathrm{p}<0.0001$ and 0.36 respectively). The eGFR calculated by cystatin $\mathrm{C}$ was also more effective in detecting renal status than eGFR calculated by creatinine with micral as the independent variable ( $R 2=0.47$ and 0.03 with $\mathrm{p}<0.0001$ and 0.29 respectively). In Group III, The correlation between micral -serum cystatin $\mathrm{C}$ and micral - serum creatinine was almost equal $(\mathrm{r}=0.698$ and $r=0.695$ respectively). However micral showed better correlation with eGFR (cys C) than with eGFR(creatinine). The $r$ values calculated were -0.588 and -0.411 respectively. Similarly regression analysis of cystatin $\mathrm{C}$ and creatinine with micral as the independent variable were almost equal ( $\mathrm{R} 2=0.48$ in both with $\mathrm{p}=0.0003)$. The area under Receiver Operating Characteristic Curve for microalbuminuria, serum cystatin $\mathrm{C}$ and serum creatinine were $0.96,0.93$ and 0.80 respectively Taking into account all the above findings it was determined that serum cystatin $\mathrm{C}$ is an earlier marker of GN than serum creatinine but both were equally good in the later stages of the disease. Serum cystatin $\mathrm{C}$ values increased as the values of micral increased and so both can be used as markers of DN in early stages. The eGFR calculated by cystatin $\mathrm{C}$ formula is more dependable than eGFR calculated by creatinine for assessing the stage of CKD in diabetes at least in the early stages of the disease. Serum creatinine can only predict DN only in late third stage of the disease when GFR has fallen substantially whereas cystatin C can predict $\mathrm{DN}$ in early stages along with appearance of microalbumin in urine. ROC curve proves serum cystatin $\mathrm{C}$ is both a sensitive and specific marker of $\mathrm{DN}$ along with micral and its performance was better than 
serum creatinine in diagnosing patients with diabetic nephropathy. These findings are consistent with studies done by Delanaye, et al., O'Callaghan, et al. and Pierre et al. [31,32].

\section{Conclusion}

The results of the study suggest that

- $\mathrm{BP}$ is a risk factor in development of $\mathrm{DN}$ in diabetic patients and it increases with the progress of the disease.

- FBS has no predictive value in the progress of DN as there was no significant rise in its value with increasing duration of the disease.

- HbAlc levels are higher in DN patients and it can be inferred that poor glycemic controls increase the chances of development of micro vascular complications.

- Hyperlipidemia is an established risk factor in development of DN in diabetics and serum cholesterol levels increase significantly in later stages of the disease.

- Urea is a non specific marker to know the renal status in patients of DN. However in the later stages of the disease when renal function is compromised to a higher degree there is significant increase.

- Microalbuminuria appears mostly after 10 years of diabetes and then increases with further increase in the duration of the disease.

- Serum creatinine values do not increase significantly in early stages of DN but show increase after there is substantial renal damage.

- Serum Cystatin levels were increased significantly in diabetics with history of more than 10 years and is earlier marker of $\mathrm{DN}$ in comparison to Serum Creatinine. The increase in levels correlates well with increase in microalbumin levels in urine in early stages of DN.

- eGFR by Cystatin C is better to know the renal status in patients of early DN detected by Microalbuminuria compared to eGFR by Creatinine.

- ROC curve proved Serum Cystatin C is more accurate marker of DN along with Micral and its performance was better than Serum Creatinine in diagnosing patients with diabetic nephropathy.

This study pointed out that both Microalbuminuria and Cystatin $\mathrm{C}$ are equally effective in detecting early diabetic nephropathy. But Cystatin $\mathrm{C}$ has the added advantage in being able to estimate eGFR to stage the diabetic nephropathy over Microalbuminuria. So Cystatin C can be suitable marker in early DN. However the study design of this thesis was cross sectional comprising of a small group of patients. The findings of this study are only suggestive. A longitudinal study with larger patient group can be done to arrive at definite conclusions.

\section{References}

1. [No authors listed] (1997) Report of the Expert Committee on the Diagnosis and Classification of Diabetes Mellitus. Diabetes Care 20: 1183-1197.

2. Kaur P, Radhakrishnan E, Rao SR, Sankarasubbaiyan S, Rao TV, et al. (2010) The metabolic syndrome and associated risk factors in an urban industrial male population in South India. J Assoc Physicians India 58: 363-366, 371.

3. Zimmet P, Alberti KG, Shaw J (2001) Global and societal implications of the diabetes epidemic. Nature 414: 782-787.
4. Ramachandran A, Ma RC, Snehalatha C (2010) Diabetes in Asia. Lancet 375 408-418.

5. International Diabetes Federation (2011) IDF Diabetes Atlas (5thedtn) International Diabetes Federation, Brussels, Belgium.

6. Zahran A, El-Husseini A, Shoker A (2007) Can cystatin C replace creatinine to estimate glomerular filtration rate? A literature review. Am J Nephrol 27 197-205.

7. Adler Al, Stevens RJ, Manley SE, Bilous RW, Cull CA, et al. (2003) Development and progression of nephropathy in type 2 diabetes: the United Kingdom Prospective Diabetes Study (UKPDS 64). Kidney Int 63: 225-232.

8. Gall MA, Hougaard P, Borch-Johnsen K, Parving HH (1997) Risk factors fo development of incipient and overt diabetic nephropathy in patients with noninsulin dependent diabetes mellitus: prospective, observational study. BMJ 314: 783-788.

9. Ranjit Unnikrishnan I, Rema M, Pradeepa R, Deepa M, Shanthirani CS, et al Prevalence and Risk Factors of Diabetic Nephropathy in an Urban South Indian Population. The Chennai Urban Rural Epidemiology Study (CURES 45)

10. Evans TC, Capell P (2000) Diabetic Nephropathy, Clinical Diabetes. 18

11. Meltzer AA, Everhart JE (1995) Unintentional weight loss in the United States. Am J Epidemiol 142: 1039-1046.

12. UK Prospective Diabetes Study group (1998) Tight blood pressure contro and risk of macrovascular and microvascular complications in type 2 diabetes. UKPDS 38. BMJ 317:703-713.

13. Adler AI, Stratton IM, Neil HA, Yudkin JS, Matthews DR, et al. (2000) Association of systolic blood pressure with macrovascular and microvascula complications of type 2 diabetes (UKPDS 36): prospective observational study. BMJ 321: 412-419.

14. [No authors listed] (1995) Effect of intensive therapy on the development and progression of diabetic nephropathy in the Diabetes Control and Complications Trial. The Diabetes Control and Complications (DCCT) Research Group. Kidney Int 47: 1703-1720.

15. Stratton IM, Adler Al, Neil HA, Matthews DR, Manley SE, et al. (2000) Association of glycaemia with macrovascular and microvascular complications of type 2 diabetes (UKPDS 35): prospective observational study. BMJ 321 $405-412$

16. Shestakova MV, Dedov II, Neverov NI, Severgina ES, Diuzhev TG, et al. (1993) [Hyperlipidemia as a factor in the development and progress of diabetic nephropathy]. Probl Endokrinol (Mosk) 39: 7-9.

17. Jandeleit-Dahm K, Cao Z, Cox AJ, Kelly DJ, Gilbert RE, et al. (1999) Role of hyperlipidemia in progressive renal disease: focus on diabetic nephropathy. Kidney Int Suppl 71: S31-36.

18. Nsonwu AC, Usoro AC, Etukudo MH, Usoro IN (2006) Influence of age, gende and duration of diabetes on serum and urine levels of zinc, magnesium, selenium and chromium in type 2 diabetics in Calabar, Nigeria. Turk. J. Bioch 3: 107-114.

19. Kundu D, Roy A, Mandal T, Bandyopadhyay U, Ghosh E, et al. (2013) Relation of microalbuminuria to glycosylated hemoglobin and duration of type 2 diabetes. Niger J Clin Pract 16: 216-220.

20. National Kidney Foundation (2002) K/DOQI clinical practice guidelines fo chronic kidney disease: evaluation, classification, and stratification. Am J Kidney Dis 39: S1-266.

21. Rahlenbeck SI, Gebre-Yohannes A (1997) Prevalence and epidemiology of micro- and macroalbuminuria in Ethiopian diabetic patients. J Diabetes Complications 11: 343-349.

22. Grover G, Gadpayle AK, Sabharwal A (2010) Identifying Patients With Diabetic Nephropathy Based On Serum Creatinine Under Zero Truncated Models. EJASA, Electron J App Stat Anal 3: 28-43.

23. Enyioma N, Obineche, Adem A (2005) Update in Diabetic Nephropathy. Int J Diabetes \& Metabolism 13: 1-9.

24. Premaratne E, Maclsaac RJ, Finch S, Panagiotopoulos S, Ekinci E, et al. (2008) Serial measurements of cystatin $\mathrm{C}$ are more accurate than creatinine-based methods in detecting declining renal function in type 1 diabetes. Diabetes Care 31: $971-973$

25. Buysschaert M, Joudi I, Wallemacq P, Hermans MP (2003) Comparative 
Citation: Brijesh M, Saurav P (2015) Comparative Study of Significance of Serum Cystatin-C, Serum Creatinine and Microalbuminuria Estimation in Patients of Early Diabetic Nephropathy. J Diabetes Metab 6: 490. doi:10.4172/2155-6156.1000490

Page 6 of 6

performance of serum Cystatin C versus serum creatinine in diabetic subject. Diabetes and Metabolism: 29: 377-383.

26. Christensson AG, Grubb AO, Nilsson JA, Norrgren K, Sterner G, et al. (2004) Serum cystatin $C$ advantageous compared with serum creatinine in the detection of mild but not severe diabetic nephropathy. J Intern Med 256: 510518

27. Peralta CA, Shlipak MG, Judd S, Cushman M, McClellan W, et al. (2011) Detection of chronic kidney disease with creatinine, cystatin $\mathrm{C}$, and urine albumin-to-creatinine ratio and association with progression to end-stage renal disease and mortality. JAMA 305: 1545-1552.

28. Mussap M, Dalla Vestra M, Fioretto P, Saller A, Varagnolo M, et al. (2002) Cystatin $\mathrm{C}$ is a more sensitive marker than creatinine for the estimation of GFR in type 2 diabetic patients. Kidney Int 61: 1453-1461.

29. Dharnidharka VR, Kwon C, Stevens G (2002) Serum cystatin C is superior to serum creatinine as a marker of kidney function: a meta-analysis. Am J Kidney Dis 40: 221-226.

30. Delanaye P, Cavalier E, Mariat C, Maillard N, Krzesinski JM (2010) MDRD or CKD-EPI study equations for estimating prevalence of stage 3 CKD in epidemiological studies: which difference? Is this difference relevant? BMC Nephrol 11: 8.

31. O'Callaghan CA, Shine B, Lasserson DS (2011) Chronic kidney disease: a large-scale population-based study of the effects of introducing the CKD-EP formula for eGFR reporting. BMJ Open 1: e000308.

32. Delanaye P, Cavalier E, Moranne O, Lutteri L, Krzesinski JM, et al. (2013) Creatinine-or cystatin C-based equations to estimate glomerular filtration in the general population: impact on the epidemiology of chronic kidney disease. BMC Nephrology 14-57. 